\title{
Openness to co-creation as a method of reducing the complexity of the environment and dynamizing companies' competitive advantages
}

\author{
Anna ADAMIK \\ Faculty of Management and Production Engineering \\ Department of Management, Lodz University of Technology, Lodz, Poland \\ anna.adamik@p.lodz.pl \\ Michał NOWICKI \\ Faculty of Management and Production Engineering \\ Department of Management, Lodz University of Technology, Lodz, Poland \\ michal.nowicki@p.lodz.pl \\ Katarzyna SZYMAŃSKA \\ Faculty of Management and Production Engineering \\ Department of Management, Lodz University of Technology, Lodz, Poland \\ katarzyna.szymanska@p.lodz.pl
}

\begin{abstract}
Openness is an expression of an enterprise's ability to adapt to changing environment conditions and its ability to cooperate with different types of partners. A given company's openness shows its readiness for the creation of dynamics of many business processes, including the creation of its competitive advantage. Due to the nature of today's enterprises' environment, mainly its "high velocity" \& "complexity" attributes, openness of companies has to be multifaceted. Organizationcustomer relationships, called co-creation, are one of such facets. The capacity for effective cocreation gives a company the ability to gain a competitive advantage along with the chance for its permanent dynamization and sustainability. The main purpose of the paper is to present the framework and algorithm of co-creation as a method of reducing the complexity of the environment and dynamizing companies' competitive advantages. A review of literature in the areas of open organization, open culture, partnership, co-creation, and competitive advantage provides a basis for understanding the process of co-creation. Collected data show that the activity of enterprises in this process is a key factor in the reduction of complexity of a company's environment and an important stimulator of the dynamization of a company's competitive advantage. The authors' own CATI questionnaire survey research conducted in Poland showed the level of preparation Polish SMEs have to co-create.
\end{abstract}

Keywords: organizational openness, co-creation, competitive advantage, dynamization, complexity of environment.

Please cite the article as follows: Adamik, A., Nowicki,M., Szymańska, K. (2018), “Openness to cocreation as a method of reducing the complexity of the environment and dynamizing companies' competitive advantages", Management \& Marketing. Challenges for the Knowledge Society, Vol. 13, No. 2 , pp. 880-896, DOI: 10.2478/mmcks-2018-0011.

\section{Introduction}

Building a competitive advantage of modern enterprises is a complex and lengthy process which requires not only an in-depth analysis but also willingness and courage to actively pursue activities related to openness to co-creation. Popularity of this issue has been growing with the increase in the volatility of the environment that forces companies to take more numerous and more organizationally difficult adjustment 
measures over an increasingly short period of time. Companies' openness to co-creation is a feature whose development is a major challenge for managers as all traditional relationships based on the hierarchy must evolve in the direction of partner relationships. This applies in particular to customers' participation in processes related to creating values or to engaging all users in dealing with challenges related to production, marketing or management (van Dijck, Nieborg, 2009). These measures are accompanied by different shades of cooperation (co-partnering, co-creation, collaboration, co-designing, submitting) and participation in joint investment projects. Such actions are based on open culture [OC] developed among partners, open resources $[\mathrm{OR}]$ and open knowledge [OK], i.e. the desire to acquire and share knowledge. The basis of co-creation is the ability to network resources, integrate conducted activities and develop voluntary cooperation in different spheres of business, therefore it is one of the basic factors that determine enterprises' innovative development (Bruns, 2007).

Co-creation is therefore not only a stimulator of the processes of shaping business competitiveness but also important protection against competitors and an instrument reducing the complexity of the environment. Unfortunately, there is still no relatively clearly structured description of the process of generating co-creation and its accompanying benefits in the literature.

The aim of the paper is an attempt to show the essence and determinants of cocreation as well as to develop a model for the use of co-creation as a method of reducing the complexity of the environment and dynamizing companies' competitive advantages. Thus defined aim has allowed the formulation of the main hypothesis:

- HG: Organizational openness [00] to co-creation makes it easier for an organization to respond to challenges stemming from the complexity of the environment and dynamize its competitive advantage.

The following specific hypotheses have been adopted:

- H1: Open Culture [OC] stimulates the readiness for co-creation;

- H2: Open Resources [OR] support the development of co-creation;

- H3: Open Knowledge [OK] facilitates the development and exploitation of co-creation.

The research presented below is used to verify the adopted hypotheses.

A literature review in the field of open organization, open culture, open resources, open knowledge, and co-creation as well as determinants of competitive advantage in the age of the complexity of environment was conducted. On the basis of data collected, an algorithm was formulated and determinants as well as possibilities of the exploitation of co-creation were described. In the next stage of the research process, empirical research showing and verifying the validity of the proposed model was carried out. Its methodology, the results and conclusions are presented in the further part of this paper. The survey method, with an original questionnaire handed out to respondents, was employed. The respondents were managers and/or owners of 251 SMEs operating in Poland. The results obtained allowed to verify the adopted hypotheses.

\section{Literature review}

For many years, the scientific literature has emphasized that organizational openness [00] needs to be seen as a key source of enterprises' competitive advantage (Caligiuri, Jacobs, Farr, 2000). Due to enterprises' openness in different areas of their business activity, they can dynamically respond to changes in a volatile environment ${ }^{1}$ and reduce

\footnotetext{
${ }^{1}$ www.open-organizations.org.uk
} 
its complexity. Therefore, openness of enterprises should be seen as a key factor in raising the competitiveness of the European economy in accordance with the EU document called Europe $2020^{2}$.

Openness, therefore, can be defined as a logical sequence of actions opening a given organization to its environment which occur within the business process aimed at creating value for companies, their owners and external partners. Openness, by definition, is an overarching concept or philosophy that is characterized by an emphasis on transparency and free, unrestricted access to knowledge and information, as well as collaborative or cooperative management and decision-making rather than a central authority (Baldwin, 2003). This means a widely understood ability to function in a changing environment and to cooperate with various partners, i.e. willingness to systematically and consciously create the dynamics of many business processes, including building a competitive advantage of enterprises. Openness refers also to a certain degree of transparency of an organization, seen especially in the context of access to information (e.g.: open resources of knowledge) (Peters, 2010). That is why [00] is associated with a number of processes that occur in each enterprise and include actions such as:

- creating new ideas, i.e. exploration of customers' needs (both external and internal);

- changing production processes according to the requirements and needs of the environment (including customers);

- developing a company through a wide coordination of the suitability of its activities for different types of stakeholders (including customers) in all the phases of its life cycle;

- adding value to existing or newly established products/services to make business partners more satisfied;

- pursuing management activities aimed at having the company stand out in the market, thus enabling it to gain a competitive advantage.

The above-mentioned actions can be considered, on the one hand, as measures of assessment, and on the other hand, as indicators of the level of [00] development (Albors-Garrigos, Rodriguez Barbera, 2012; Baldwin, Gelletly, 2003; Edward, Delbridge, Munday, 2005). The implementation of these actions allows the company concerned to increase the degree of its openness. This degree can be assessed on many planes. The internal ones include:

- personnel and collaborators;

- the company's activity in the field of research and development;

- technological advancement;

- the quality of technical infrastructure.

They create open culture [OC], open resources [OR] and open knowledge $[\mathrm{OK}]$ in enterprises. External determinants of [0O] are generated mostly by external partners such as: competitors, customers and suppliers, universities, research and development units, and others. Their willingness to cooperate and share knowledge (knowledge partnering) (Adamik, Flaszewska, 2015), the level of trust they have towards their business partners, their focus on the customer, and their social corporate responsibility are only some of the most common determinants of openness.

\footnotetext{
${ }^{2}$ https://ec.europa.eu/info/business-economy-euro/economic-and-fiscal-policy-coordination/eu-economicgovernance-monitoring-prevention-correction/european-semester/framework/europe-2020-strategy_en [20.11.2017].
} 
Owners and managers of enterprises have the decisive voice in how relations with these stakeholders are built. Their opinion in this regard is determined by their awareness of the widely understood culture of openness. For companies to be organizationally open, their managers need to learn how to effectively manage relationships with the environment. In order to open an organization to its environment, first the conditions for openness within the company must be created.

Therefore, 00 can be considered as the main principle which sets the company's attitude not only towards its employees, customers or competitors, but towards its whole environment. Openness is fluid, multi-dimensional and questioned (Robertson, 2015). Due to the nature of the nowadays identified "high velocity" and complexity of the environment, 00 must therefore involve many planes. The proposed model includes such key - in the authors' opinion - planes. In the framework of these planes, openness of enterprises must be reflected in their sensitivity, flexibility and ability to quickly adapt to the conditions and needs of the environment and to build modern concepts and business models for this purpose. This approach allows to significantly reduce the complexity of the environment. Today, the development of enterprises' competitive potential without their openness to such actions is impossible. The implementation of this idea requires full operational efficiency, i.e. the ability to translate the strategy into processes, systems and structures as well as the ability to respond to unexpected situations, especially to market opportunities.

The development of the so-called open organizational culture [OC] ${ }^{3}$ is a prerequisite (basis) for the creation of [00]. Such culture should be characterized by openness to learning as well as promoting and encouraging flexibility and creativity (such features are indicated by e.g.: Purcarea, et. al., 2013; Alboros-Garrigos, Rodriguez Barbera, 2012) in order to dynamize a company's development opportunities. For the purpose of the paper, it is assumed that [OC] is the type of culture characterized by the so-called openness to space, which means openness to change, openness to uncertainty, and openness to flexibility. Openness to space comprises a company's activities relating to the creation of conditions for various types of networks and relationships with a widely understood environment (Adamik, 2016). This openness should apply to an enterprise's resources as well as resources of its customers, suppliers, and competitors [Open Resources - OR]. In fact, it should encompass entities that have complementary skills and do not hesitate to use them in relationships of co-creation with other sectors (this is the basis for co-partnering, co-creation, collaboration, co-designing, and submitting). Readiness for cooperation and implementation of innovative changes is associated with openness to new knowledge in different areas [Open Knowledge - OK]. The ability to identify and respond to new threats generated by the environment is particularly important. A company must take these actions in order to limit the risk of errors and to effectively exploit opportunities emerging in the environment (dynamic reducing of the complexity of the environment). As a result of these activities, a company is able to dynamize and sustain its developed competitive advantage and successfully deal with the situation of dynamic changes in its environment. In today's organizations, the process of changes leading to $[\mathrm{OC}]$ is increasingly important. [OC] should: be open to the environment, promote cooperation with the environment, ensure freedom of relationships using for this purpose not only the potential of employees but also external partners, be open to new knowledge and changes, as well as the resulting errors (Adamik, Szymańska, 2016). In addition, [OC] is focused on the implementation of

\footnotetext{
${ }^{3}$ If an organization seeks to increase its efficiency, prepare and go through the process of change, one should look at
} 
unique visions and strategies while ensuring the discipline of participants integrated around these new activities.

$[O C]$ is therefore "the backbone of any enterprise" (Kegan, Laskow, 2016), a plan which plays a strategic role allowing to adaptively manage both open resources [OR], and open knowledge [OK]. This fact is important since, according to today's managers, building an open organization based on [OC] and supported by open, focused on knowledge management, resources takes many years (Whitehurst, 2015). Despite the fact that each organization is open in a different manner as it is a unique example of [OC], the following characteristics that most often generate [00] can be determined: transparency, cohesion/identity, uniqueness, adaptability, collaboration, and community.

$[\mathrm{OC}]$ and $[\mathrm{OR}]$ are ultimately a solid foundation for the third element designating organizational openness to co-creation - open knowledge. [OK] is a common good from which everyone can benefit, a staff member and an organization itself, or its business partners. Moreover, everyone can participate in its development ${ }^{4,5}$. Knowledge is open if everyone has free access to it, can use, modify and share it with others, subject to the requirements of, at most, the determination of the sources of its origin or maintaining its openness. This plane serves to ensure interoperability, i.e. full compliance occurring between organizational openness and its other two planes - open organizational culture and open resources (see Figure 1).

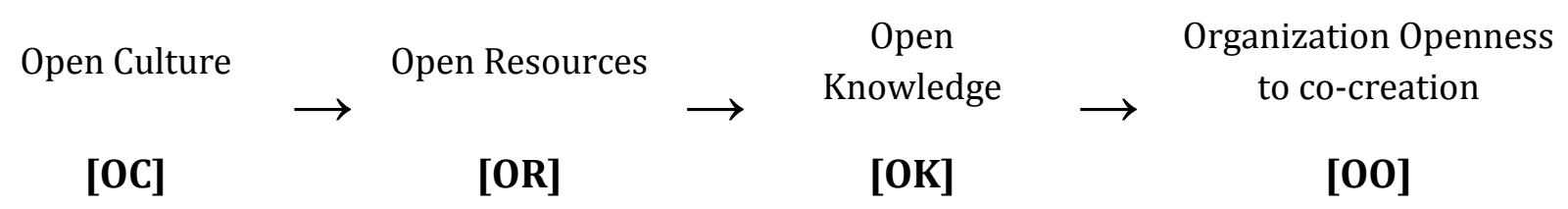

Figure 1. Openness to co-creation

Source: The authors' own elaboration

Prahalad and Ramaswamy are considered to be the main promoters of the concept of co-creation (Prahalad, Ramaswamy, 2004 a b; Ramaswamy, Ozcan, 2014). Popularity of co-creation has been growing along with the increasing dynamics of changes and volatility of the environment which forces companies to take more numerous and more organizationally difficult adjustment measures implemented over an increasingly shorter period of time (see: Mahr, Lievens, Blazevic, 2014; Hakanen, 2014; Grönroos, Voima, 2013; Syam, Pazgal, 2013; Ind, Fuller, Trevail 2012; Bogers, Afuah, Bastian, 2010; Ramaswamy V., Gouillart F. 2010; Hoyer, et. al., 2010).

Co-creation is the process of involving interested stakeholders from the outside of a given company, its customers, business partners, etc. in the process of developing new products and services in order to use their experience in the course of discussions and exchange of ideas. Co-creation is about joint creation of value by the company and the customer. It is not the company trying to please the customer. It is about experiencing the business as consumers do in real time, it is a continuous dialogue about the possibility of co-constructing new, innovative, personalized co-creation experiences and its environments (see: Parhalad, Ramaswamy, 2004 a,b). The basis for the effective

\footnotetext{
${ }^{4}$ http://www.opensource.org/docs/osd, [20.11.2017];

${ }^{5}$ Definition of Free Cultural Works, (http://freedomdefined.org) [20.11.2017]
} 
application of this method is the previously described openness of a company (Galvagno, Dalli, 2014).

Co-creation changes the center of gravity in the design of products/services from the inside of a company to its environment, which provides a way to stimulate innovativeness. The co-creation processes are characterized by interdisciplinarity, interactivity, iteration, and looking through the prism of value creation for the environment. These actions are not based on the genius of an individual, but on the strength of cooperation and relationships. As a result, co-creation provides a company with a value which is not to be underestimated - an opportunity to not only gain a competitive advantage over its current market rivals but also a chance for the continuous dynamization and sustainability of this competitive advantage. In this context, particular attention should be paid to the nature of the relationships found on the organization-customer plane. This type of relationship is considered today as a stimulator of processes shaping competitiveness of enterprises and important protection against potential competitors.

Both business practitioners and scientists that deal with the field of management agree that in order to build a strong and stable competitive position, organizations need to seek new ways and possibilities for development. It seems that one of them is the implementation of the concept of co-creation. On the basis of the above-presented considerations, an initial version of the framework and algorithm of the process of co-creation as a method of reducing the complexity of the environment and dynamizing companies' competitive advantage was developed (see: Figure 2). The presented algorithm includes traditionally identified elements of co-creation (O'Hern and Rindfleisch, 2010; Rindfleisch and O'Hern, 2015; Sandor, 2017): open culture [1], open resources [2], open knowledge [3], submitting [S], tinkering [T], co-designing [CD] and collaboration [CL]. Three new ones were also identified: dynamic competitive advantage (upper horizontal axis); complexity reduction (right vertical axis); uniqueness (bottom horizontal axis). 


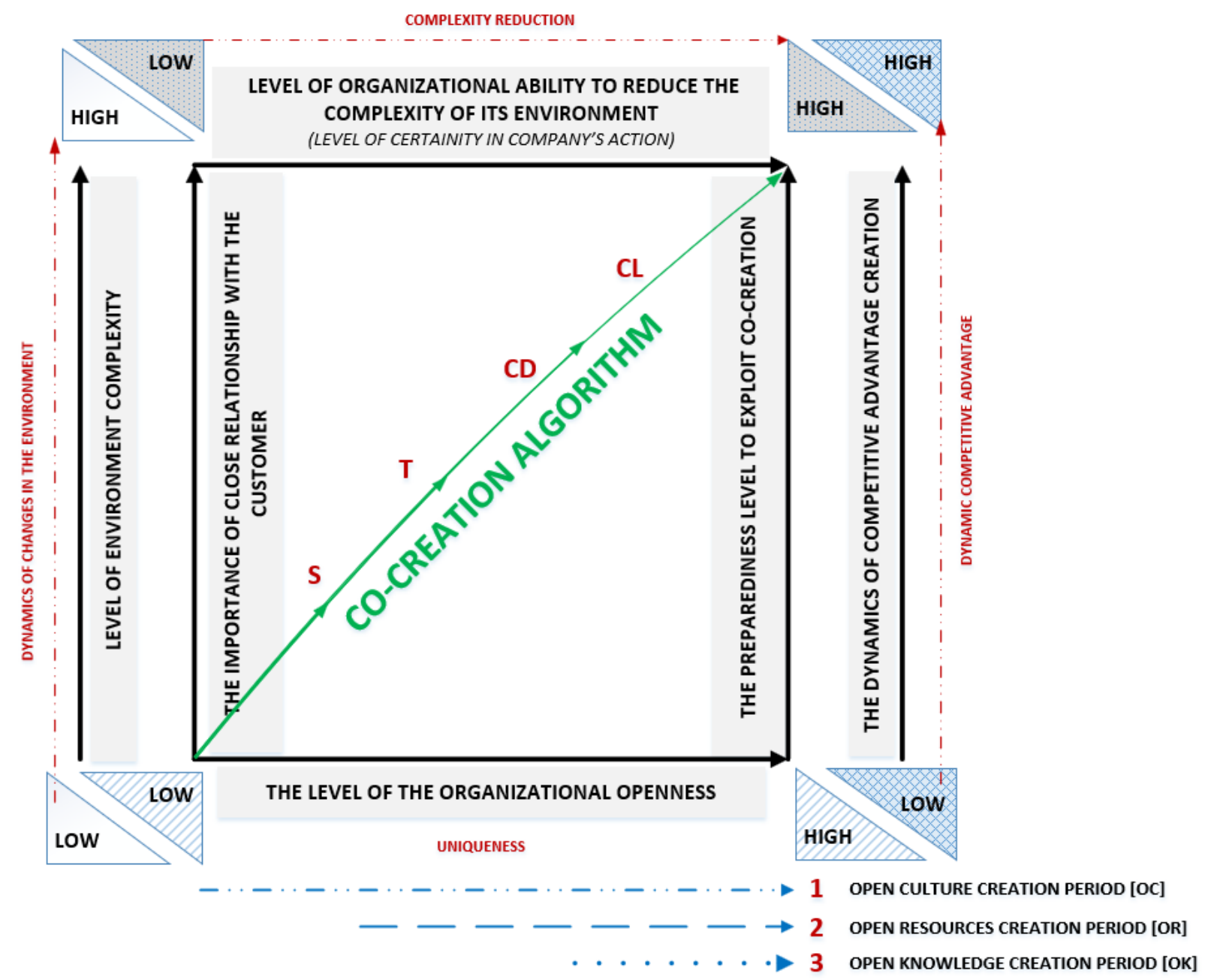

$\mathrm{S}=$ submitting

$\mathrm{T}=$ tinkering

$\mathrm{CD}=$ co-designing

$\mathrm{CL}=$ collaboration

Figure 2. Framework and algorithm of the process of co-creation

Source: The authors' own elaboration.

The model integrates six axes that jointly determine the framework of the co-creation algorithm. The bottom horizontal axis shows the level of organizational openness [00] and assumes that its increase proceeds towards the right, which is accompanied by hierarchically ordered and gradual opening of a given organization in specific areas of [OC], [OR] and [OK]. The upper horizontal axis shows the level of a given organization's ability to reduce the impact of the complexity of the environment in which it operates, and thus increase the certainty of its activity. Similarly to the bottom axis, it is assumed that the increase occurs along the axis to the right, which means that it is positively correlated with the level of organizational openness [00]. The vertical axes on the left represent the levels of importance of having close relationships with customers and the complexity of the organizational environment.

They are oriented in the same direction, which should be interpreted as a manifestation of the belief that as the complexity of a given organization's environment increases, it should strive to build stronger relationships with its customers. Such an action in theory should allow: lowering a given organization's sensitivity to changes in its environment, faster adaptation to changes or even their anticipation, the possibility of making better business decisions using knowledge and 
information about expectations, preferences and needs of the organization's customers obtained from them. The vertical axes on the right illustrate the level of a given organization's readiness to use the co-creation concept and the related level of this organization's ability to create a dynamic competitive advantage. The axes collectively determine the framework that forms the plane of the co-creation algorithm. By marking "values" (low/ high) of the "parameters" described above, the algorithm allows us to read at what stage of the co-creation implementation a given organization is and what activities it should conduct to dynamize its competitive advantage. In the algorithm, the steps for the development of co-creation were arranged so that they would take into account the impact and changes in the levels of "variables" displayed on the axes. Due to the fact that the [1/2/3] elements as the basis for the co-creation concept are described above, the next part of the paper will be devoted to presenting: Submitting [S], Tinkering [T], Co-designing [CD], and Collaborating [CL], which show the specificity of operational activities undertaken by an organization during co-creation to build and dynamize its competitive advantage.

SUBMITTING is the simplest form of co-creation. Importantly, the company exercises control over the contribution activity by placing constraints on the basic design, contribution size etc. and also over the selection activity by choosing the winning contributions. A product/service launched to the market is a "final" product, i.e. one that is not subject to further improvement/changes. At this level, only open-culture is required as this co-creation form is characterized by the lowest level of contribution provided by customers, as they are asked to communicate more fully formed concepts, with the company maintaining full control over the new product development process.

An example of this type of cooperation is the work of the Concept Craft art workshop. According to the founder: "... the studio is a place where unusual ideas clash with knowledge and skills developed over the years, providing a chance to create unconventional products, fully tailored to the requirements and expectations of customers." 6 . The company's cooperation with the customer basically comes down to determining: the general purpose and the main functions of the product to be created (1), the raw materials/materials from which it is to be made (2), the buyer's budget/price the buyer is ready to pay for the final product (3) and his/her hobbies/interests that provide an inspiration for design work (4). Then a design process takes place consisting in the preparation of several concepts from which the customer chooses one. The final stage is the creation of the ordered "work/object", e.g.: a rack for a bottle of wine with the function of a decorative lamp, created on the basis of worn parts from the compressor engine operating in the refrigeration unit (see: http://www.cc-craft.pl/realizacje/wineholder).

TINKERING is a customer co-creation model that involves procurement of contributions from the public by the company, a comprehensive and scrupulous examination of the contributions, selection of the most promising and enterprising contributions by the company and finally implementation of the contributions. That is why one can say that in tinkering the public exercises control over the contribution activity while the company exercises control over the selection activity - the customer comes up with a variety of ideas for the organization, whereas the selection is defined by multiple parameters of the company, and eventually the company usually releases the final product. After being released to the market, the product may be subject to modification and extension processes many times. During the debut of the product on

\footnotetext{
${ }^{6}$ http://www.cc-craft.pl/o-pracowni
} 
the market, or later, the company usually releases tools enabling further development of the product by customers. In order for the modified version of the product to hit the market, acceptance (on the part of the company) of the changes made in the product is required, as the company is still its only official distributor. This means open culture and a weak-moderate level of open resources.

One example of how Tinkering can extend the lifecycle of a product is the Steam Workshop operating within the Steam platform whose motto is "Create, discover and download content for your games" (see: http://steamcommunity.com/workshop). This application allows the community to prepare custom modifications and extensions to games/programs/applications available on the Steam platform. Steam Workshop users usually have at their disposal most of the tools used by the creators of the original product to develop it, although they can also use their own. Developed solutions (extensions/add-ons) are then sent to the Steam platform, either as modifications officially supported by the developer/distributor of the original product/service, or as unofficial versions. In the latter case, the developer of the original product/service is relieved of liability if after installing the modification/extension, there are any problems in the operation of the product/service.

The example of Tinkering is X:COM 2 game. From the moment of its launch in 2016, through the platform, each of the game owners can install as add-ons to the original version more than 2,000 various modifications changing to varying degrees the gameplay and players' experience.

Summing up, Tinkering is where customers make modifications to commercially available products, some of which are incorporated into later releases. Downside is that the company may end up competing with customer modifications. According to Rindfleisch and O'Hern, Tinkering is an attractive proposition for companies as it provides a level of control and restriction for the customers, whilst the company still obtains valuable and critical insight from the customers on their preferences and expectations. However, it differs from collaborating in that the company implements a much higher degree of control, structure and boundaries on what the customer should collaborate on (Rindfleisch and O'Hern, 2015).

CO-DESIGNING is a type of cooperation in the framework of co-creation in which when developing a new product, the company presents to the general public an overall product concept (project/prototype) that can be significantly modified/expanded thanks to the involvement of stakeholders. The degree of advancement of the final product depends on the level of involvement of stakeholders. This means open culture and open resources along with a low level of open knowledge. Co-designing is a narrower and more targeted cooperation between the company and a smaller group of customers. As collaborating, it relies on significant input from the customers free of significant boundaries, yet the customer group that engages with the company is much smaller, making the management and steering of the process easier (Rindfleisch and O'Hern, 2015). The most important feature that distinguishes Tinkering from Co-designing is that this form of co-creation involves placement of constraints by the company on the contribution activity and selection of the winning contributions by the contributors themselves.

Companies that use Co-designing often run their business activity based on a business model that allows the intensive use of Crowdfunding 7 /Crowdsourcing ${ }^{8}$, for

\footnotetext{
${ }^{7}$ Crowdfunding to start a project.

${ }^{8}$ Gathering ideas, suggestions, and partial solutions enabling the implementation of a project.
} 
example Kickstarter ${ }^{9}$. It is used by individual creators (private individuals) as well as small, independent development studios in the field of electronic entertainment and computer games. For example, creating the 1st and 2nd part of game called Divinity: Orginal Sin, the developer studio Larian Studios LLC using the Kickstarter platform "promised" that after reaching the next levels of community contribution, the game on the day of its release would have additional content. The goal of the public fundraising on Kickstarter - financing the release of the first part of the game - was achieved in 12 days. The pace of the fundraising surprised even the developers from the Larian studio. Only 12 hours were needed to raise the funds for the sequel, the 500,000 USD which was the minimum amount guaranteeing the launch of the project. During that time, the project account accumulated deposits amounting to more than 605 thousand dollars from more than 14 thousand users, and still a month was left till the end of the fundraising period. Thanks to the involvement of the player community, on the day of its release, compared to the "basic" version, the game was expanded, among others by (www.kickstarter.com/projects/larianstudios/divinity-original-sin-2):

- the "Strategist" mode for players looking for challenges $\rightarrow$ the fundraising ceiling of $\$ 700000$ was reached;

- a more comprehensive and unique character development system (advanced skill tree) $\rightarrow$ the fundraising ceiling of $\$ 1350000$ was reached;

- the introduction of "Hall of Echoes", i.e. the content which consisted of additional: game stories, locations, quests, unique items and mobs $\rightarrow$ the fundraising ceiling of \$1 500000 was reached;

- the introduction of relationship/emotion mechanics between the characters directed by the player, thanks to which unique threads in the story/plot of the game may appear $\rightarrow$ the fundraising ceiling of $\$ 1750000$ was reached.

At the level of COLLABORATING, the company releases to the market a product which was developed with full cooperation of the customer that has a very wide discretion as to product parameters (components, functionality, production method, distribution). Each collaborating participant is open to the suggestions of others, actively using open resources and the involvement of the so-called community (Internet forums, blogs, vlogs). In the case of electronic products (software, games, applications, etc.), they are released in the "open source" version, i.e. made available along with the complete source code and tools that were used to create them. Modified versions, in order to be available on the market, do not need to obtain the consent of the creator of the original version. As a result of this form of cooperation, the modified version of the product may differ materially from its original. It can fulfill a completely different function and/or satisfy completely different needs. Everyone who wants can freely develop/modify the product and then make it public. The creator of the original product is open to sharing knowledge, actively supports co-creators of modified versions, while personally developing his/her own version of the product. This means that at the moment "on the market" there are many competing versions of the product created as part of the collaborating mechanism. This means the entire sequence: open culture + open resources + open knowledge, as Collaborating involves the most active engagement on the part of the customer among the four classifications. It is defined as a totally open environment, with a seamless engagement and cooperation between the

\footnotetext{
${ }^{9}$ Kickstarter is an enormous global community built around creativity and creative projects. Its mission is to help artists, musicians, filmmakers, designers, and other creators on their path of finding the resources and support they need to make their ideas a reality (see more: www.kickstarter.com).
} 
company and the customers. Collaborating is an ongoing initiative and process without a finite end, and thus supports companies in their efforts to stay ahead of competition as well as to drive innovation (Rindfleisch and O'Hern, 2015).

Linux (see: www.linux.com), the operating system created using free and open software FLOSS - Free/Libre Open Source Software, is an example of solutions resulting from the use of collaboration. Its source code can be freely used, modified and distributed. The following are its most important distributions (independent of each other versions developed by various contributors) (distrowatch.com): Linux Mint, Fedora, Ubuntu, openSUSE, PCLinuxOS, CentOS/Red Hat Enterprise Linux, Arch Linux, Mandriva Linux, Slackware, Debian GNU/Linux.

\section{Methodology}

To illustrate the algorithm proposed in the paper with research results, a group of SMEs operating in Poland was selected. The empirical material was collected from a large research sample. In the years 2009-2015, 251 SMEs were surveyed in this way. It was a primary indirect survey using the method of the questionnaire handed out to the respondents. The research tool was a survey questionnaire. The study covered enterprises employing up to 249 people operating in Poland. The respondents conducted commercial and service activities (31.9\%), production, trade and service activities (22.3\%), service activities (18.3\%), retail (16.7\%), and wholesale trade (10\%.). Customer orientation resulting in a wide range of products and services was, in the opinion of the respondents, a business strength of $49 \%$ of them. Among respondents, nearly 70\% declared that they would implement close partner cooperation with customers. Small enterprises were the most active in this area (see Table 1).

Table 1. Participants in partner cooperation of the surveyed SMEs

\begin{tabular}{|c|c|c|c|}
\hline \multirow{2}{*}{ Company types } & \multicolumn{3}{|c|}{ Participants in SMEs' partner cooperation (\%) } \\
\cline { 2 - 4 } & Suppliers & Customers & Competitors \\
\hline SMEs total (\%) & 80.9 & 67.7 & 38.2 \\
\hline Micro (N=170) & 79.6 & 63.5 & 36.5 \\
\hline Small (N=60) & 83.3 & 78.3 & 43.3 \\
\hline Medium (N=21) & $100(\mathrm{~N}=21)^{*}$ & $76(\mathrm{~N}=16)^{*}$ & $38(\mathrm{~N}=8)^{*}$ \\
\hline
\end{tabular}

* due to the small size of the group of medium companies surveyed, the number of respondents and not the percentage was given for this group of enterprises

Source: The authors' own research.

In the course of the research, for each of the planes fundamental for co-creation [OC/OR/OK], a few parameters describing the planes were proposed. Providing their assessment, the respondents showed their commitment to the co-creation processes. They expressed their opinions on a scale from 1 to 3 , where: "1" meant low, "2" average, and "3" high level of commitment. This approach allowed to identify the level of preparation of the respondents in the field of shaping and using [OC/OR/OK]. In addition, the respondents were asked for the assessment of co-creation usefulness in their everyday functioning.

\section{Results and discussions}

When assessing the preparation of the surveyed SMEs on three planes that are of key importance for co-creation in terms of openness of their organizational culture, open resources and open knowledge [OC, OR and $\mathrm{OK}$, a level close to the average was 
identified on each of these planes (see Table 2). The respondents' openness in the area of OR seems to be only slightly above average.

Analyzing in detail the $\mathrm{OC}$ area, it was possible to determine that within that area the respondents had the most developed skills related to communication with customers (2.7) and the least developed skills generating the frequency of cooperation with customers (1.3). Small enterprises seem to be the most culturally open (2.0). They are already so developed, and yet still not rigid with bureaucratization and various procedures, that this result seems justified.

Analyzing the OR plane, it was determined that the respondents had the most developed skills in the area of harmonious coordination of their resources with customers (2.7), and the least developed those responsible for jointly solving production and market problems with them (1.3). Such a result is the effect of, on the one hand, the desire on the part of these SMEs to meet the needs and requirements of their stakeholders, and, on the other hand, the effect of still small openness to co-creation among their customers. The highest, above-average, OR value was generated by the surveyed medium-sized enterprises (2.2). It can be concluded that the level of available resources-related potential facilitates the decision to open this potential to co-creation and close relations with business partners.

Investigating the OK plane, it was identified that the level of its development is most strongly determined by the ability of the respondents to choose partners and their parameters (resources, skills, and above all, their openness to cooperation). The most useful are relationships with customers that stimulate the respondents to conduct innovative activities (2.3), i.e. demanding customers, who engage in joint projects, sharing - depending on the needs - their experience, knowledge or other resources. This plane is supported to the least degree by the respondents' ability to share with customers the risk associated with market activities (1.0). The research indicates that micro-enterprises and medium-sized enterprises are somewhat more efficient than small enterprises in the field of openness to acquiring and sharing knowledge. It seems, therefore, that, on the one hand, operational flexibility and, on the other hand, bargaining power can be stimulators of co-creation.

Table 2. Matrix of the degree of customer relationship development in the process of co-creation in micro, small and medium enterprises

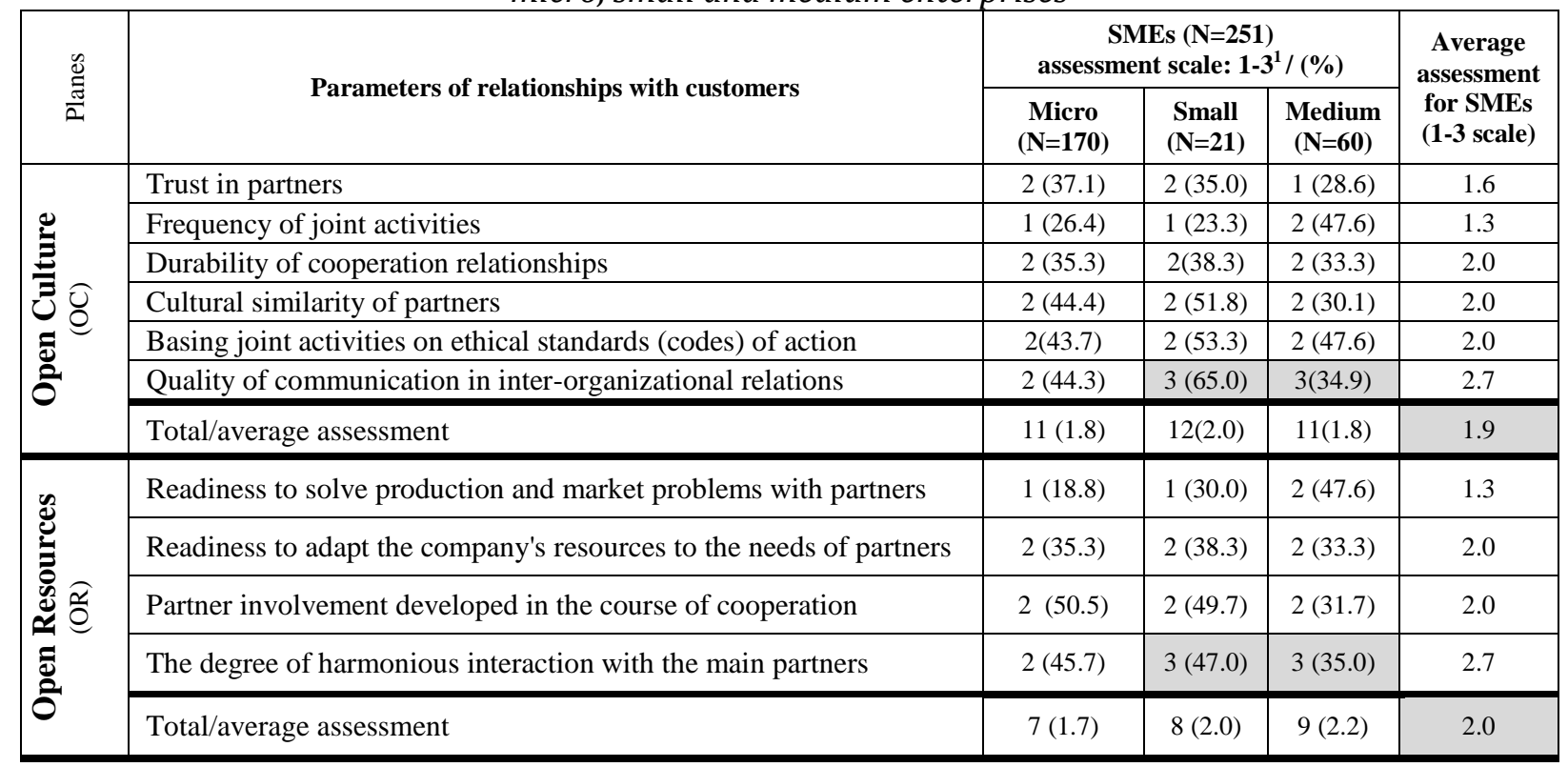




\begin{tabular}{|c|c|c|c|c|c|}
\hline \multirow{5}{*}{ 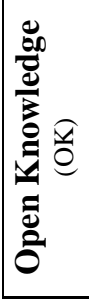 } & Openness to close inter-organizational cooperation & $1(32.3)$ & $2(51.5)$ & $3(71.4)$ & 2.0 \\
\hline & Readiness to share market risk with partners & $1(12.6)$ & $1(10.1)$ & $1(28.6)$ & 1.0 \\
\hline & Openness to the informal/private nature of relationships & $2(39.5)$ & $1(26.7)$ & $1(9.5)$ & 1.3 \\
\hline & The influence of partners on the company's innovativeness & $3(45.0)$ & $2(44.8)$ & $2(20.6)$ & 2.3 \\
\hline & Total/average assessment & $7(1.7)$ & $6(1.5)$ & $7(1.7)$ & 1.6 \\
\hline & Overall preparation of the respondents for co-creation $(1-3)^{2}$ & 1.8 & 1.9 & 1.9 & 1.8 \\
\hline
\end{tabular}

Source: The authors' own research.

Generally, the level of preparation of the surveyed SMEs for effective implementation of co-creation should be assessed as rather average. There is still much to do on each of the key co-creation planes. First of all, it is necessary to create in enterprises a culture that is more open to external suggestions, ready to experiment and make mistakes (the so-called error-embracing culture) and a culture capable of adapting and creating extensive networks of cooperation and collaboration. These activities, although they are not the easiest ones, constitute the most important aspect of ongoing changes in the transition through successive levels of organizational openness. This may result in a greater ability of small and medium enterprises to be open on various planes integrating these activities, i.e. building innovative concepts and business models, adapting company resources to partners' needs, improving communication with partners, jointly solving production and market problems with partners, pursuing harmonious interaction with partners, implementing risk diversification, etc.

The customer relationship parameters assessed by the respondents allow us to see a strong relationship between organizational openness [00] along with its components [OC, OR and $\mathrm{OK}]$ and co-creation of small and medium-sized enterprises. The level of awareness of these relations on the part of the companies surveyed testifies to their ability to exploit relationships with the environment and build a competitive advantage based on them. As the research indicates, unfortunately, these relationships are not yet satisfactory.

Out of the twenty-three benefits of co-creation rated by companies of all sizes, the following were mentioned:

- micro enterprises develop a better reputation/company image $32.9 \%$ of the micro companies surveyed), achieve higher profitability of the company's activities $(31.7 \%)$ and gain the possibility of fulfilling non-standard orders $(30.5 \%)$;

- small companies develop a better reputation/company image (56.7\% of the small businesses surveyed), gain the possibility of fulfilling non-standard orders (48.3\%), achieve higher profitability of the company's activities (45\%);

- medium companies achieve better satisfaction of customer needs $52.4 \%$ of the medium-sized companies surveyed), develop a better reputation/company image (47.6\%), and achieve a better competitive position in the region (42.8).

Generally, in the opinion of more than $77.7 \%$ of the respondents, close relationships with customers (co-creation) were important for the dynamization of their development and competitive advantage, and in the case of $48.2 \%$ of them played a very important role. It was particularly felt by micro enterprises $(43.7 \%$ of these enterprises surveyed) - (see Table 3). 
Table 3. The importance of co-creation for developing competitiveness in the opinion of the surveyed SMEs

\begin{tabular}{|l|c|c|c|c|}
\hline \multirow{2}{*}{$\begin{array}{c}\text { Having close relationships } \\
\text { with customers is... }\end{array}$} & \multicolumn{4}{|c|}{ SMEs (\%) } \\
\cline { 2 - 5 } & $\begin{array}{c}\text { Total } \\
(\mathrm{N}=251)\end{array}$ & $\begin{array}{c}\text { Micro } \\
(\mathrm{N}=170)\end{array}$ & $\begin{array}{c}\text { Small } \\
(\mathrm{N}=60)\end{array}$ & $\begin{array}{c}\text { Medium } \\
(\mathrm{N}=21)\end{array}$ \\
\hline important & 77.7 & 72.5 & 71.7 & $85.7 \%(\mathrm{~N}=18)^{*}$ \\
\hline very important & 21.9 & 19.8 & 25.0 & $23.8 \%(\mathrm{~N}=5)^{*}$ \\
\hline extremely important & 48.2 & 43.7 & 8.3 & $23.8 \%(\mathrm{~N}=5)^{*}$ \\
\hline
\end{tabular}

* due to the small size of the group of medium companies surveyed, the number of respondents and not the percentage was given for this group of enterprises

Source: The authors' own research.

In-depth analyses indicate that the surveyed SMEs are able to also distinguish other, and in their opinion the most beneficial, effects of co-creation. Most frequently mentioned are the ones presented below (see Figure 3).

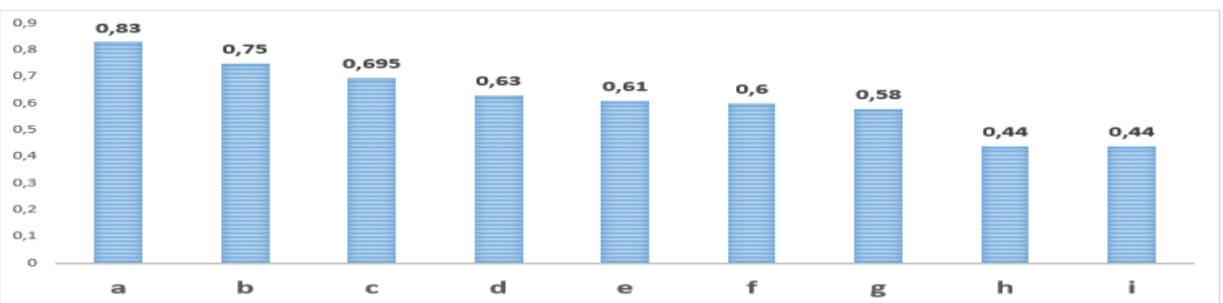
*** Possibility of [\%]:
e reducing the costs of gathering information about the market
a gaining loyal customers
b better recognition of customers' needs and minimizing the risk of losing market opportunities
c improving the efficiency of market activities
f narrowing the scope of activity necessary to specialize and strengthen its position
g shaping the company's reputation and image effectively
h cooperation with representatives of the artistic community
i establishing cooperation with strong partners
d fulfilling non-standard orders

Figure 3. Most common co-creation benefits

Source: The authors' own elaboration.

Co-creation constitutes an important source of opportunities to improve the efficiency of enterprises, stimulate the processes of building and maintaining their competitiveness, and develop their ability to function in a complex and dynamically changing environment.

\section{Conclusion}

At the beginning of the paper, the assumption was made that organizational openness [00] to co-creation facilitates reducing the complexity of the environment (MH). The research conducted has confirmed that open culture [OC] stimulates readiness for cocreation (H1) and open resources [OR], fosters the development of co-creation(H2) as well as openness in the field of acquiring and sharing knowledge [OK], and facilitates building a competitive position based on uniqueness (H3). Bearing in mind the above, it can be stated that the issues raised in this study are of significant importance for the development of enterprises. The analyses carried out showed that openness to co-creation is today a valuable and unique source of competitive advantage for a growing number of enterprises. It seems to be particularly advantageous for companies with a greater resource potential, and therefore for medium-sized companies 
among the surveyed enterprises. At the same time, it provides a great opportunity to support the ability of smaller companies, which are by nature more flexible and open to the environment, to compete effectively. Such orientation allows them to significantly dynamize activities as well as to reduce the complexity of the environment. This is confirmed by well-developed worldwide studies (see: Keeys, Huemann, 2017; Lombardo S., Cabiddu F., 2017; Cossío-Silva F.J., et. al. 2016; Mathisa, et. al., 2016; Weber, Van der Laan, 2014). Similar conclusions can also be drawn by the analysis of research results and the review of Polish scientific literature, although its body is more modest.

The model of the framework and algorithm of the process of co-creation proposed in the paper seems an interesting complement to the existing research. The analysis of Polish SMEs conducted with its use indicates a fairly low level of their readiness and involvement in activities related to co-creation and the development of OC-OR-OK. This has shown the directions of actions that should be taken to effectively compete under the conditions of environment complexity.

In the framework of the research work, the authors sought to maintain the appropriate methodological rigor aimed at ensuring a high degree of objectivity and reliability of inference. Despite this, the formulated model and the results of the research are characterized by certain limitations. They mainly result from the inability to specify all factors determining co-creation. For this reason, the focus was on the most important of those factors. Therefore, the considerations do not show the entire spectrum of issues, which encourages further research in this area.

\section{References}

Adamik A. (2016), The mechanism of building competitiveness through strategic partnering, Management, Vol. 20, No. 1, pp. 292-309.

Adamik A., Flaszewska S. (2015), The positive potential of the organization and knowledge partnering, Journal of Positive Management, Vol. 6, No. 3, pp. 29-40.

Adamik A., Szymańska K. (2016), The technological entrepreneurship capacity and partnering as elements of an open culture of small and medium-sized enterprises: case study of Poland [in:] M.H. Bilgin, H. Danis, (eds.) Entrepreneurship, Business and Economics, Vol. 1, Eurasian Studies in Business and Economics, Vol. 3/1 Proceedings of the 15th Eurasian Business and Economics Society Conference, Springer.

Albors-Garrigos J., Rodriguez Barbera R. (2012), Impact of public funding on firms innovation performance. Analisis of internal and external moderating factors, International Journal of Innovation Management, Vol.15, No. 6, pp. 1297-1322.

Baldwin R. (2003), Openness and growth: what's the empirical relationship, http://www.nber. org/papers/w9578 [assess: 15.11.2017].

Bogers, M., Afuah, A., \& Bastian, B. (2010), Users as innovators: A review, critique, and future research directions. Journal of Management, Vol. 36, No. 4, pp. 857-875.

Bruns A. (2007), Produsage, Towards a broader framework for user-led content creation, Creativity and Cognition: Proceedings of the 6th ACM SIGCHI Conference on Creativity and Cognition, ACM, Washington.

Caligiuri P.M., Jacobs R.R., Farr J.L. (2000), The attitudinal and behavioral openness scale: Scale development and construct validation, "International Journal of Intercultural Relations", Vol. 24, No. 5, pp. 27-46

Cossío-Silva F.J., Revilla-Camacho M.A., Vega-Vázquez M., Palacios-Florencio B. (2016), Value co-creation and customer loyalty, Journal of Business Research, Vol. 69, No. 5, pp. 1621-1625. 
Edward T., Delbridge R., Munday M. (2005), Understanding innovation in small and medium-sized enterprises: a process manifest, Technovation, N0.25, Cardiff.

Galvagno M., Dalli D. (2014), Theory of Value Co-Creation: A Systematic Literature Review, Managing Service Quality, Vol. 24, No. 6, pp. 643-683.

Grönroos, C., \&Voima, P. (2013), Critical service logic: Making sense of value creation and co-creation. Journal of the Academy of Marketing Science, Vol. 41, No. 2, pp. 133-150.

Hakanen, T. (2014), Co-creating integrated solutions within business networks: The KAMteam as knowledge integrator. Industrial Marketing Management, Vol. 43, No. 7, 1195-1203.

Hoyer, W. D., Chandy, R., Dorotic, M., Krafft, M., Singh, S. S., \& Chandy, R. K. (2010), Consumer Cocreation in new product development. Journal of Service Research, Vol. 13, No. 3, pp. 283-296.

Ind, N., Fuller, C., \&Trevail, C. (2012), Brand together: How co-creation generates innovation and re-energizes brands. London: Kogan Page Publishers.

Keeys L.A., Huemann M., (2017), Project benefits co-creation: Shaping sustainable development benefits, International Journal of Project Management, Vol. 35, No. 6, pp. 1196-1212.

Kegan R., Laskow, L. L. (2016), An Everyone Culture: Becoming a Deliberately Developmental Organization Hardcover, Harvard Business Review Press.

Lombardo S., Cabiddu F., (2017), What's in it for me? Capital, value and co-creation practices, Industrial Marketing Management, Vol. 61, pp. 155-169.

Mahr, D., Lievens, A., \&Blazevic, V. (2014), The value of customer cocreated knowledgeduring the innovation process. Journal of Product Innovation Management, Vol. 31, No. 3, pp. 599-615.

Mathisa E.F., Kim H.L., Uysal M., Sirgy J.M., Prebenses N.K., (2016), The effect of co-creation experience on outcome variable, Annals of Tourism Research, Vol. 57, pp. 62-75.

O'Hern, M., \& Rindfleisch, A. (2010), CUSTOMER CO-CREATION: A TYPOLOGY AND RESEARCH AGENDA, Review of Marketing Research, Vol. 6, pp. 84-106.

Peters M. (2010), The Idea of Openness: Open Education and Education for Openness, [in:] The Encyclopaedia of Educational Philosophy and Theory, M. Peters, T. Besley, A. Gibbons, B. Žarnić, P. Ghiraldelli (eds.): http://eepat.net/doku.php?id=open_education_and_educa $\neg$ tion_for_openness.

Prahalad, K. C.,Ramaswamy V. (2004a),The Future of Competition: Co-creating Unique Value with Customers. Boston: Harvard Business School Press.

Parhalad C. K., Ramaswamy V. (2004b), Co-creation experiences: The next practice in value creation, The Future of Competition: Co-creating Unique Value with Customers, Harvard Business School Press.

Purcarea I., Benavides E., Maria del Mar; Apetrei A. (2013), Innovation and knowledge creation: perspectives on the SMEs sector, Management Decision, Vol. 51, No. 5, pp. 1096-1107.

Ramaswamy V., Ozcan K. (2014), The co-creation paradigm. Stanford University Press.

Ramaswamy V., Gouillart F. (2010), The Power of Co-Creation: Build It with Them To Boost Growth, Productivity, and Profits. Free Press.

Rindfleisch, A., \& O'Hern, M. (2015). Brand remixing: 3D printing the Nokia case. In Brand Meaning Management (pp. 53-81). Emerald Group Publishing Limited.

Robertson B.J. (2015), Holacracy: The New Management System for a Rapidly Changing World Hardcover, Henry Holt and Co. 
Sandor N. (2017), Co-Creation: A platform to create more loyal and long-term customer relationships in the aviation supply industry, on-line: http://www.divaportal.se/smash/get/diva2:1147033/FULLTEXT01.pdf [access: 16.12.2017]

Syam, N. B., Pazgal, A. (2013), Co-creation with production externalities. Marketing Science, Vol. 32, No. 5, pp. 805-820.

Weber M.E.A, van der Laan D.H. (2014), Does Customer Co-creation Really Pay Off? An Investigation into the Firm's Benefits from Customer Involvement in New Product and Service Development, [in:]Brunoe T., Nielsen K., Joergensen K., Taps S. (eds.) Proceedings of the 7th World Conference on Mass Customization, Personalization, and Co-Creation (MCPC 2014), Aalborg, Denmark, February 4th 7th, 2014. Lecture Notes in Production Engineering. Springer, Cham.

Whitehurst J. (2015), The Open Organization: Igniting Passion and Performance, CEO of Red Hat, Harvard Business Review Press.

van Dijck J., Nieborg D. (2009), Wikinomics and its discontents of Web 2.0 business manifestos, New Media \& Society, Vol. 11, No. 4, pp. 855-874.

***Distrowatch official website, distrowatch.com

***Fredomdefined official website, http://freedomdefined.org

***Steamcommunity official website http://steamcommunity.com/workshop

***Cc-craft official website, Wineholder page http://www.cccraft.pl/realizacje/wineholder

*** Cc-craft official website http://www.cc-craft.pl/o-pracowni

***Opensource official website http://www.opensource.org/docs/osd

${ }^{* * *}$ Europa.eu official website https://ec.europa.eu/info/business-economyeuro/economic-and-fiscal-policy-coordination/eu-economic-governancemonitoring-prevention-correction/european-semester/framework/europe2020-strategy_en

***Kickstarter official website www.kickstarter.com.

***Kickstarter official website, Project page www.kickstarter.com/projects/larianstudios/divinity-original-sin-2.

***Linux official website, www.linux.com.

*** Open Organisations official website, www.open-organizations.org.uk 